\title{
Water Resistance and Optical Properties of Optical Adhesives Containing Strong Hydrophobic Components
}

\author{
Takeyuki SAWAmOTO ${ }^{\dagger, \dagger \dagger}$ and Susumu IKEDA* \\ Graduate School of Science and Engineering, Yamagata University, Yonezawa 992-8510, Japan \\ ${ }^{*}$ Faculty of Engineering, Yamagata University, Yonezawa 992-8510, Japan
}

(Received October 6, 2003; Accepted December 29, 2003)

\begin{abstract}
To produce high performance optical adhesives, adhesives were prepared by mixing triethoxy vinylsilane (TVSi) as a silane coupling agent into basic compositions consisting of $15 \mathrm{wt} \%$ 2-hydroxyethyl methacrylate (HEMA), oligo-siloxanyl dimethacrylate (SiMA) and acrylicacid tricyclo $\left[5,2,1,0^{2,6}\right]$ decane (TCDA). When the composition includes TCDA from 43 to $69 \mathrm{wt} \%$, copolymers polymerized from the composition exhibit high adhesion strength to glass, good optical transparency and excellent water-resistance. The high quality of the adhesives comes from microscopically homogeneous structures of the copolymers in which all components are mixed randomly. KEY WORDS Adhesive Composition / Phase Structure / Water Resistance / Silane Coupling Agent /
\end{abstract}

In assembling optical devices, optical adhesives are important for combining optical parts such as optical fibers, lenses and prisms. The adhesives must have high adhesion strength to glass and excellent optical transparency. Fluorine-containing optical adhesives are such adhesives. ${ }^{1,2}$ We reported other optical adhesives consisting of dimethacryloxypropyl oligo-dimethylsiloxane (SiMA), 2-hydroxyethyl methacrylate (HEMA) and acrylicacid tricyclo[5,2,1, $\left.0^{2,6}\right]$ decane (TCDA). ${ }^{3,4}$

For an optical device that needs higher-level reliability, optical adhesives having excellent water resistance are required, because moisture in air often deteriorates adhesion strength. ${ }^{5-7}$ This manuscript describes a trial to add high water resistance to adhesives and obtain excellent optical adhesives. We discuss the structural origin of the high efficiency that optical adhesives possess.

This paper proposes new adhesive compositions of SiMA, HEMA, TCDA and triethoxy vinylsilane (TVSi). These compositions include TVSi as a silane coupling agent to produce high-performance optical adhesives with good water resistance. Silane coupling agents, well known in the field of fiber-glass reinforced plastics, improve mechanical strength even in a humid atmosphere. ${ }^{8-10}$ Fiber glass and the coupling agent are connected by chemical bonds under suitable conditions. ${ }^{11}$ Little research on adhesives including silane coupling agents has been performed so far, because the silane coupling agents added to the hydrophilic adhesives are unstable and are hydrolyzed and condensed easily by water absorbed by the hydrophilic groups. ${ }^{12}$ For copolymers consisting of SiMA, HE-
MA, TCDA and TVSi, it is expected that the strong hydrophobicity of SiMA and TCDA protects the silane coupling agent from water.

\section{EXPERIMENTAL}

\section{Materials}

The chemical structures of components in the adhesive compositions are shown in Table I. HEMA includes a hydroxyl group and has good adhesive strength to glass in dry condition. SiMA has good wettability to glass surface because of the low cohesive force of polydimethylsiloxane chains. HEMA is not dissolved in SiMA. Substituting TCDA for a part of SiMA, however, makes SiMA and HEMA compatible. Adhesive compositions are shown in Table II. Triethoxy vinylsilane (TVSi) was used as a silane coupling agent. Ethoxy groups of TVSi produce $\mathrm{Si}-$ O-Si bonds with glass surface, ${ }^{9}$ and vinyl groups of TVSi are expected to have chemical affinity for the compositions. A small amount of 1-hydroxycyclohexyl phenylketone (HCPK) was added to initiate radical photopolymerization.

\section{Adhesion Test}

A pair of Pyrex glass rods with polished edge $(\phi 20 \times 25 \mathrm{mmH}$ and $\phi 6 \times 10 \mathrm{mmH})$ was used as adherends for an adhesion test. The pair was bonded by the adhesive compositions photopolymerized by irradiation of ultravoilet rays $5 \mathrm{~mW} \mathrm{~cm}{ }^{-2}$ from a $400 \mathrm{~W}$ high-pressure mercury lamp for $10 \mathrm{~min}$.

Compressive shear force was applied to the interface of the bonded glass rods using a universal tester

\footnotetext{
${ }^{\dagger}$ To whom correspondence should be addressed (E-mail: sawamoto@mub.biglobe.ne.jp).

${ }^{\dagger}$ Present address: ADELL Corporation, Taito-ku, Tokyo 110-0005, Japan.
} 
Water Resistance and Optical Properties of Optical Adhesives

Table I. Properties of adhesive components

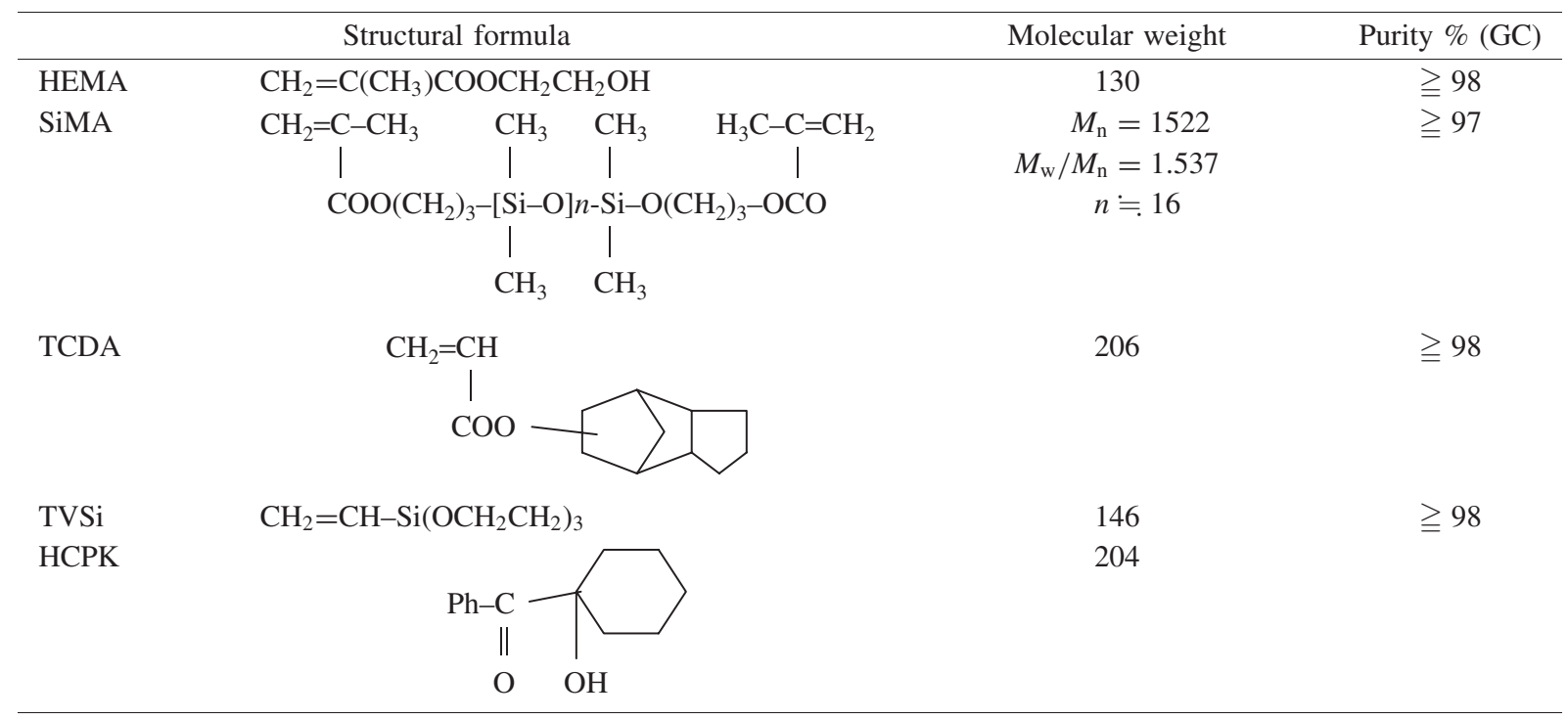

Table II. Prepared adhesive compositions (wt $\%$ )

\begin{tabular}{ccccc}
\hline Run no. & SiMA & HEMA & TCDA & TVSi \\
\hline 1 & 70 & 15 & 15 & \\
2 & 55 & 15 & 30 & \\
3 & 35 & 15 & 50 & \\
4 & 15 & 15 & 70 & \\
5 & 0 & 15 & 85 & \\
& & & & \\
6 & 69 & 15 & 11 & 5 \\
7 & 57 & 15 & 23 & 5 \\
8 & 46 & 15 & 34 & 5 \\
9 & 34 & 15 & 46 & 5 \\
10 & 23 & 15 & 57 & 5 \\
11 & 11 & 15 & 69 & 5 \\
12 & 0 & 15 & 80 & 5 \\
R1 & 100 & & & \\
R2 & & 100 & & \\
R3 & & & 100 & \\
R4 & & & & \\
R5 & 95 & & & \\
R6 & & 95 & & 5 \\
\hline
\end{tabular}

with the apparatus shown in Figure 1. The adhesion test was carried out on dry and wet samples immersed in hot water at $80^{\circ} \mathrm{C}$ for $20 \mathrm{~h}$, or set in saturated water vapor at $40^{\circ} \mathrm{C}$ for $168 \mathrm{~h}$.

\section{Transparency and Turbidity Measurements}

Test films were made by photopolymerization from adhesive compositions with thickness $0.3 \mathrm{~mm}$ placed between transparent, low alkaline-glass substrates. The sample included a pair of glass substrates. The refractive index of the glass was 1.53. Theoritical upperlimit of optical transmittance of the sample was $c a$. $91 \%$, because the measured transmittance included

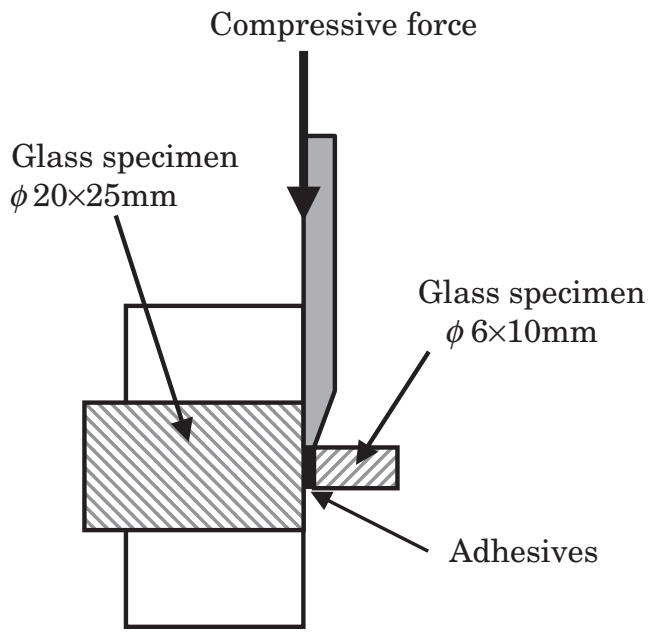

Figure 1. Schematic diagram of adhesion test.

light reflection loss due to mismatching of refractive indices at the interfaces between low alkaline-glass and air, and between the glass and adhesives. Turbidity of the polymerized samples was estimated by optical transparency measured by a spectrometer.

\section{Microscopic Observations}

The polymerized samples of $50 \mu \mathrm{m}$ thickness were tinted in $1 \mathrm{wt} \%$ Rhodamine B solution at $60{ }^{\circ} \mathrm{C}$ for $10 \mathrm{~min}$. The phase structures of the samples were observed with a 900-power optical-microscope. Optical absorbance of the tinted samples was measured by a spectrometer.

\section{Water Absorption of Samples}

Water absorption was measured after immersion in water for $20 \mathrm{~h}$ at room temperature. 
Table III. Properties of prepared polymers and copolymers

\begin{tabular}{|c|c|c|c|c|c|}
\hline \multirow[b]{2}{*}{ Run no. } & \multirow{2}{*}{$\begin{array}{c}\text { Optical } \\
\text { transmittance } \\
\% T \text { at } 450 \mathrm{~nm}\end{array}$} & \multicolumn{3}{|c|}{ Adhesion strength } & \multirow{2}{*}{$\begin{array}{c}\text { Water } \\
\text { absorption } \\
(\%)\end{array}$} \\
\hline & & $\begin{array}{c}\text { Dry } \\
\left(\mathrm{N} \mathrm{mm}^{-2}\right)\end{array}$ & $\begin{array}{l}80^{\circ} \mathrm{C} \mathrm{Wet} \\
\left(\mathrm{N} \mathrm{mm}^{-2}\right)\end{array}$ & $\begin{array}{l}40^{\circ} \mathrm{C} \mathrm{Wet} \\
\left(\mathrm{N} \mathrm{mm}^{-2}\right)\end{array}$ & \\
\hline 1 & 47.5 & 6.0 & 0.7 & 1.3 & 3.2 \\
\hline 2 & 62.1 & 13.7 & 0.8 & 4.2 & 3.0 \\
\hline 3 & 88.4 & 14.1 & 0.1 & 1.7 & 2.4 \\
\hline 4 & 90.6 & 14.7 & 0.2 & 2.3 & 1.9 \\
\hline 5 & 90.5 & 10.1 & 1.6 & 1.4 & 2.0 \\
\hline 6 & 50.2 & 11.3 & 3.5 & 3.6 & 3.5 \\
\hline 7 & 60.8 & 7.9 & 2.6 & 3.6 & 2.6 \\
\hline 8 & 83.4 & 10.7 & 6.8 & 6.9 & 2.0 \\
\hline 9 & 90.8 & 14.0 & 12.2 & 12.1 & 1.3 \\
\hline 10 & 90.6 & 15.6 & 14.7 & 14.5 & 1.5 \\
\hline 11 & 91.0 & 16.3 & 15.1 & 14.0 & 2.1 \\
\hline 12 & 91.2 & 8.3 & 15.4 & 6.7 & 2.5 \\
\hline R1 & 90.6 & 4.5 & 0.2 & 1.9 & 0.5 \\
\hline $\mathrm{R} 2$ & 90.7 & 10.1 & 2.0 & 3.2 & 71.2 \\
\hline R3 & 90.8 & 6.0 & 1.3 & 5.0 & 0.7 \\
\hline R4 & 91.0 & 2.0 & 2.3 & 3.4 & 1.0 \\
\hline R5 & 39.5 & 8.0 & 1.4 & 5.8 & 65.8 \\
\hline R6 & 91.0 & 5.3 & 13.2 & 3.7 & 0.8 \\
\hline
\end{tabular}

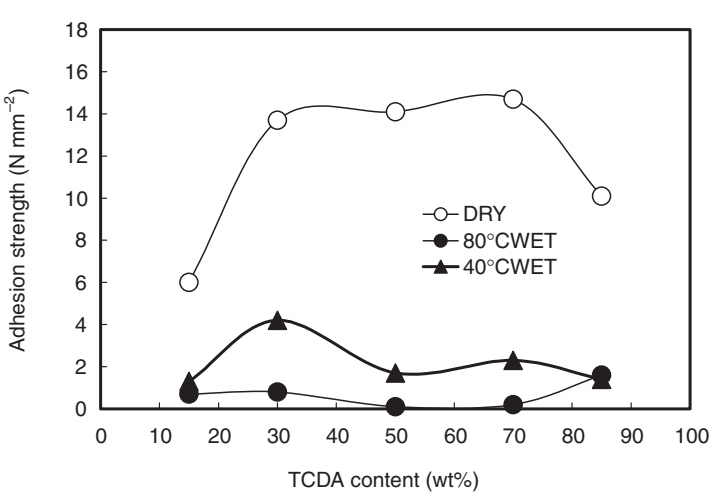

Figure 2. Adhesion strength of copoly(SiMA/HEMA/ TCDA). $\bigcirc$ : dry condition, $\bullet$ : after immersion in hot water at $80^{\circ} \mathrm{C}$ for $20 \mathrm{~h}, \boldsymbol{\Delta}$ : after kept in humid atmosphere at $40^{\circ} \mathrm{C}$ for $168 \mathrm{~h}$.

\section{RESULTS AND DISCUSSION}

Experimental results are summarized in Table III.

\section{Adhesion Strength}

Authors reported new optical adhesives consisting of SiMA, HEMA and TCDA easily copolymerized by ultraviolet irradiation at room temperature. . $^{3,4}$ Figure 2 shows adhesion strength of the copoly(SiMA/HEMA/TCDA) as a function of TCDA content and strength to increase with TCDA content in the dry condition and become $14 \mathrm{~N} \mathrm{~mm}^{-2}$ at TCDA from

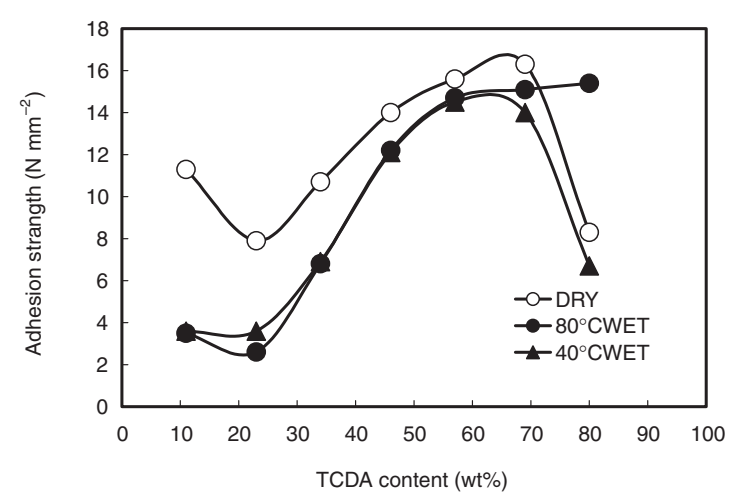

Figure 3. Adhesion strength of copoly(SiMA/HEMA/ TCDA/TVSi). $\bigcirc$ : dry condition, $\bullet$ : after immersion in hot water at $80^{\circ} \mathrm{C}$ for $20 \mathrm{~h}$. $\boldsymbol{\Delta}$ : after kept in humid atmosphere at $40{ }^{\circ} \mathrm{C}$ for $168 \mathrm{~h}$.

30 to $70 \mathrm{wt} \%$. Figure 2 shows adhesion strength to decrease remarkably in a humid atmosphere. The strength of the wet samples immersed in hot water significantly dropped to less than about $1 \mathrm{~N} \mathrm{~mm}^{-2}$.

Figure 3 illustrates adhesion strength of copoly $(\mathrm{Si}$ MA/HEMA/TCDA/TVSi) samples at constant TVSi to enhance water-resistance. Adhesion strength increased with TCDA content in the dry condition. The strength of wet samples increased with TCDA content. Adhesives having high water resistance were obtained at TCDA from 46 to $69 \mathrm{wt} \%$. Water resistance depends strongly on TCDA content. In samples with low TCDA, the water-resistant effect of TVSi 


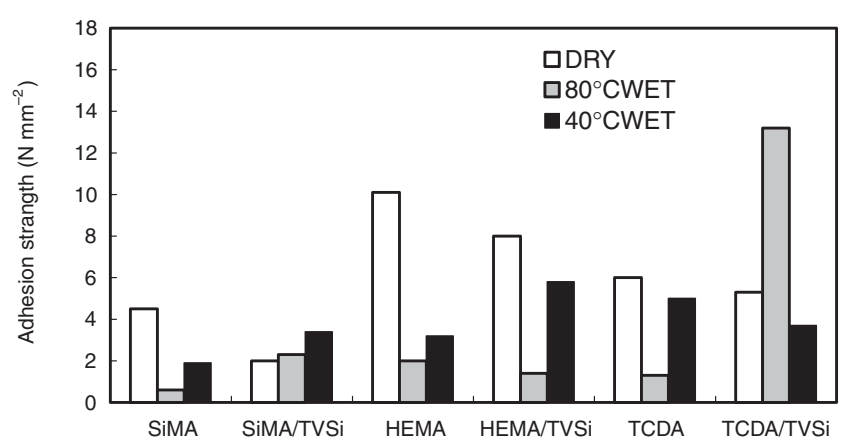

Figure 4. Adhesion strength of homopolymers of SiMA, HEMA and TCDA and copolymers with TVSi. $\square$ : dry condition, $\square$ : after immersion in hot water at $80^{\circ} \mathrm{C}$ for $20 \mathrm{~h}$. $\square$ : after kept in humid atmosphere at $40^{\circ} \mathrm{C}$ for $168 \mathrm{~h}$.

was not found. In those samples, SiMA and HEMA are separated, resulting in the formation of regions of poly(HEMA) and poly(SiMA). Poly(HEMA) is invaded by water as seen in Table III and water-resistant effect of TVSi is lost.

Replacement of SiMA by TCDA promoted random copolymerization of SiMA, HEMA and TCDA and microscopically homogeneous structure was formed when TCDA content increased. The homogeneous structure of the copolymer in which all components are mixed randomly, improves water resistance.

Adhesive strength at TCDA content higher than $69 \%$ in dry and humid conditions at $40^{\circ} \mathrm{C}$ decreased again due to plasticizer effect of residual monomers of TCDA.

Figure 4 compares adhesive strength of homopolymers of SiMA, HEMA, and TCDA and copolymers with TVSi with copoly(SiMA/HEMA/TCDA/TVSi). Adhesiveness was very bad in comparison with that of copoly(SiMA/HEMA/TCDA/TVSi). Copoly(TC$\mathrm{DA} / \mathrm{TVSi}$ ) showed strange behavior that wet samples immersed in hot water at $80^{\circ} \mathrm{C}$ had stronger adhesion than dry samples. Residual monomers in samples after ultraviolet irradiation at room temperature may polymerize because of annealing at $80^{\circ} \mathrm{C}$ for long time (20 h).

The cause of the survival of monomers and short chains is that the glass transition temperature of poly(TCDA) of $c a .120^{\circ} \mathrm{C}$ is much higher than room temperature. Residual monomers and short chains of TCDA cannot meet with other molecules at room temperature when surrounded by immobile long chains. This does not occur in other samples except TCDA because the glass transition temperature of poly(Si$\mathrm{MA}$ ) is below $-100^{\circ} \mathrm{C}$ due to oligo-dimethylsiloxane ${ }^{13}$ and poly(HEMA) is at most $60{ }^{\circ} \mathrm{C}^{14}$

\section{Optical Transparency}

Optical transmittance at $450 \mathrm{~nm}$ of copoly(SiMA/ HEMA/TCDA/TVSi) is plotted against TCDA con-

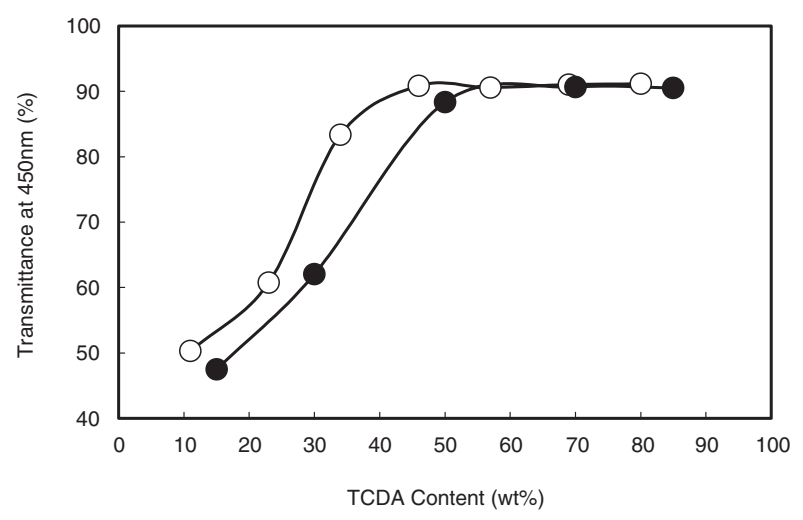

Figure 5. Optical transmittance of copoly(SiMA/HEMA/ TCDA) and copoly(SiMA/HEMA/TCDA/TVSi). $\bigcirc: \operatorname{copoly}(\mathrm{Si}-$ MA/HEMA/TCDA/TVSi) • : copoly(SiMA/HEMA/TCDA).

tent in Figure 5, where transmittance of copoly(SiMA/HEMA/TCDA) is plotted for comparison. Transmittance increased with TCDA and leveled off at $46 \mathrm{wt} \%$. Transmittance at $46 \mathrm{wt} \%$ TCDA content was $91 \%$ nearly equal to the theoretical upper-limit of the sample, which includes the light reflection loss due to mismatching of refractive indices between air and glass.

The same was observed for samples without TVSi, but samples including TVSi showed higher transparency than without TVSi at TCDA content below $c a$. $50 \mathrm{wt} \%$.

Transparency of the copolymer samples varied with TCDA. In Figure 6, absorbance spectra in the frequency range of visible radiation are plotted against reciprocals of the 4th power of wavelength. Samples No. 6 and No. 7 with TCDA at less than $23 \mathrm{wt} \%$ were turbid and light absorbance decreased with TCDA. Absorbance spectra increased nonlinearly with increase in $\lambda^{-4}$, indicating the existence of a fairly large heterogeneous structure that scatters light. Light absorbance of sample 8 with TCDA $34 \mathrm{wt} \%$ varied linearly with $\lambda^{-4}$. Rayleigh scattering may thus occur due to parti-

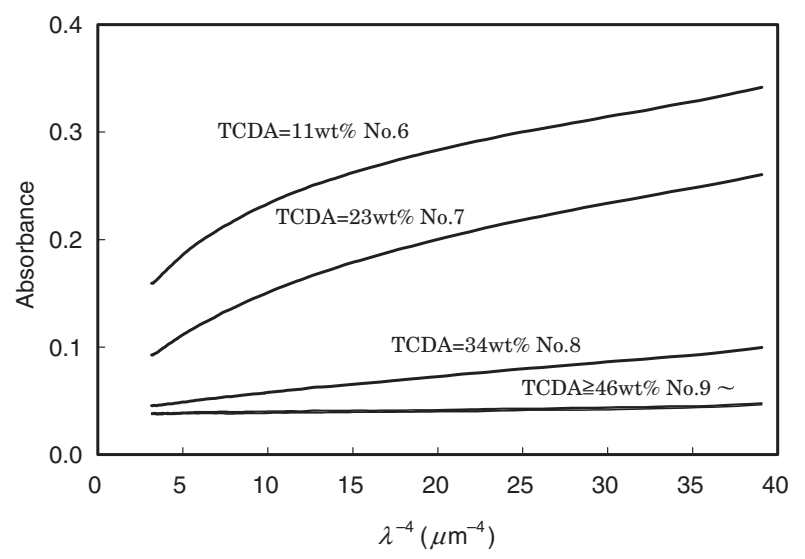

Figure 6. Optical absorbance vs. $\lambda^{-4}$ plots of copoly(SiMA/ HEMA/TCDA/TVSi). 


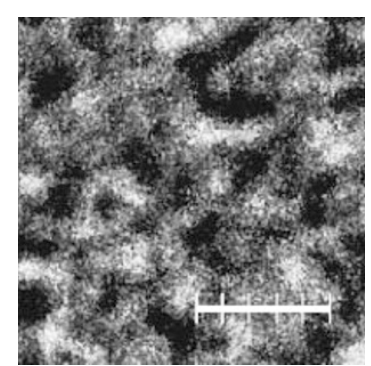

No.6
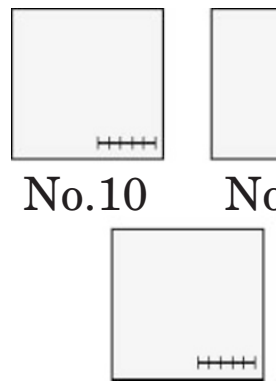

No.12

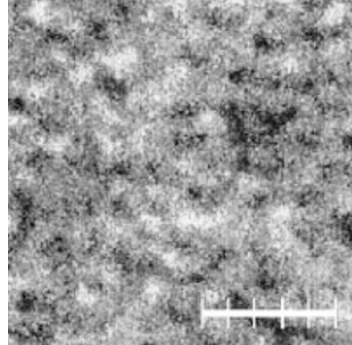

No.7

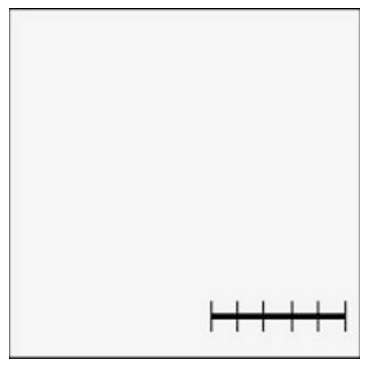

$\mathrm{R} 4$

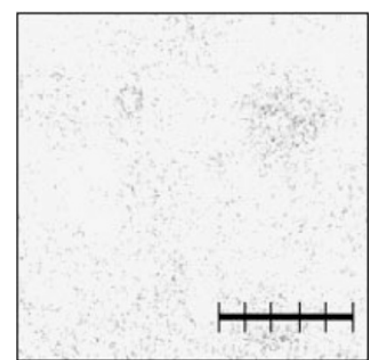

No.8

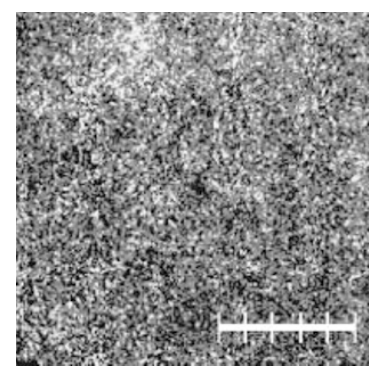

R5

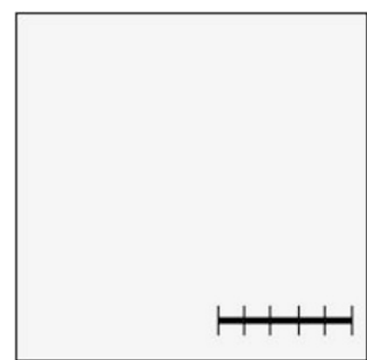

No.9

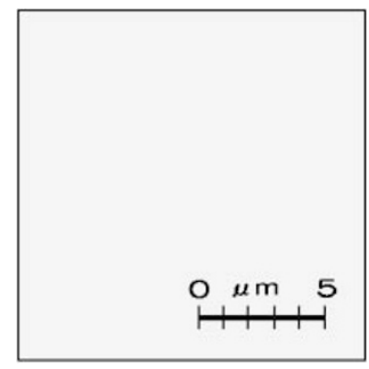

R6

Figure 7. Microscopic images of copoly(SiMA/HEMA/TCDA/TVSi), copoly(HEMA/TVSi), copoly(SiMA/TVSi) and copoly(TC$\mathrm{DA} / \mathrm{TVSi}$ ) after soaking in $1 \mathrm{wt} \%$ Rhodamine B solution at $60^{\circ} \mathrm{C}$.

cles less than $0.1 \lambda .^{15,16}$ Samples with TCDA more than $46 \mathrm{wt} \%$ were colorless and transparent, and absorbance spectra were nearly constant against $\lambda$. There is thus no heterogeneous structure that scatters light. Samples 9, 10,11 and 12 exhibited good transparency in all visible light regions like optical glass or resin such as PMMA.

\section{Microscopic Observation}

Microscopic images of samples 6 to 12 and from R4 to R6 are shown in Figure 7. In samples 6 and 7 with TCDA less than $23 \mathrm{wt} \%$, heterogeneous structures were observed, showing regions tinted well by Rhodamine B and which are over $1 \mu \mathrm{m}$ in diameter. Rhodamine B tints only the HEMA component in these three homopolymers of SiMA, HEMA and TCDA as seen in Figure 7. The tinted regions thus form by the aggregation of the HEMA component. The size of a region decreased with TCDA content and a fine phase-separated structure was formed at $34 \mathrm{wt} \%$ of TCDA (No. 8). A microscopically homogeneous structure was obtained at TCDA more than $46 \mathrm{wt} \%$, supporting the considerations in Figures 3, 5 and 6.

Optical absorbance of samples at $595 \mathrm{~nm}$, due to the absorption of Rhodamine B, is plotted against TCDA in Figure 8. Absorbance at $650 \mathrm{~nm}$ was subtracted from the original value at $595 \mathrm{~nm}$ to eliminate the influence of light scattering. Absorbance at $0 \mathrm{wt} \%$ TCDA was calculated from sample R5 to make HEMA content equal to that of other samples. Absorbance decreased monotonically with TCDA up to

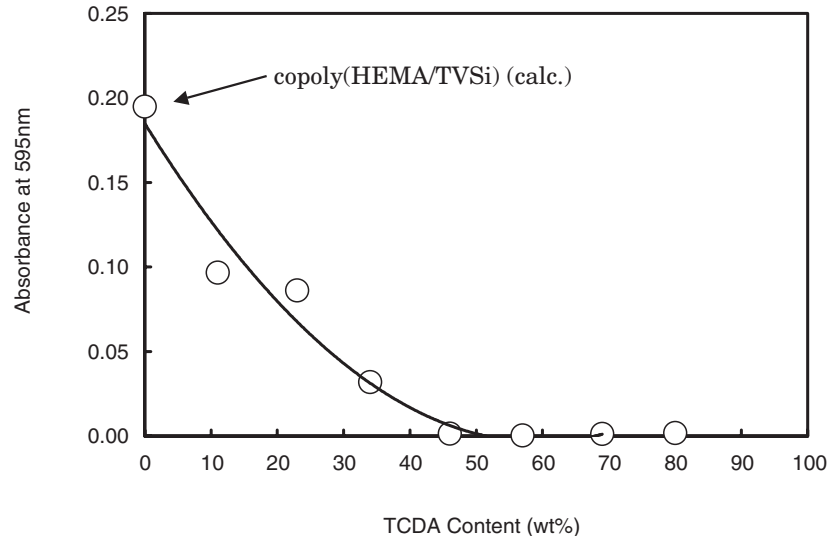

Figure 8. Optical absorbance of copoly(SIMA/HEMA/ TCDA/TVSi) after soaking in $1 \mathrm{wt} \%$ Rhodamine B solution at $60^{\circ} \mathrm{C}$.

$46 \mathrm{wt} \%$, although the quantity of HEMA was the same. The structure of the copolymer may thus change continuously with TCDA content.

In samples with small amounts of TCDA, the HEMA component was condensed by itself, as indicated by the tinted regions for samples 6 and 7 in Figure 7 . The size of the condensed region decreased with TCDA, because some HEMA monomers were copolymerized with SiMA and TCDA. Optical absorbance also decreased. Above TCDA content of $46 \mathrm{wt} \%$, nearly all HEMA monomers were copolymerized with SiMA and TCDA randomly. A microscopically homogeneous structure was formed and not tinted by aqueous RhodmineB solution, since HEMA component was mixed microscopically with SiMA and 
TCDA components having strong hydrophobicity. Thus, the effect of TVSi was protected from water.

\section{CONCLUSIONS}

SiMA/HEMA/TCDA/TVSi with HEMA of 15 wt $\%$, TVSi of $5 \mathrm{wt} \%$ and TCDA of 46 to $69 \mathrm{wt} \%$ was high-quality optical adhesives showing high adhesion strength to glass, excellent water resistance and good optical transparency in regions visible light. They are promising optical adhesives for assembling micro optical components in optical devices and medical apparatus. Excellent properties of the adhesives are due to homogeneous structures of polymers copolymerized randomly.

\section{REFERENCES}

1. T. Maruno and K. Nakamura, J. Appl. Polym. Sci., 142, 2141 (1991).

2. T. Maruno, K. Nakamura, and N. Murata, Macromolecules, 29, 2006 (1996).

3. T. Sawamoto and S. Ikeda, presented at 7th SPSJ International Polymer Conference, Yokahama, Japan, Oct. 26-29,
1999.

4. T. Sawamoto and S. Ikeda, Kobunshi Ronbunshu, 57, 425 (2000).

5. T. Fukushima, J. L. Ferracane, T. Horibe, and T. Okabe, Dent. Mater. J., 7, 1 (1988).

6. H. Ohno, Y. Araki, K. Endo, Y. Yamabe, and I. Kawashima, Dent. Mater. J., 15, 183 (1996).

7. R. A. Jurf and J. R. Vinson, J. Mater. Sci, 20, 2979 (1985).

8. A. Dufence and C. Lacabanne, Polymer, 36, 4417 (1995).

9. H. Ishida and J. Koenig, J. Polym. Sci., Polym. Phys. Ed., 18, 233 (1980)

10. S. Kurata and N. Yamazaki, Dent. Mater. J., 12, 127 (1993).

11. C. H. Chiang and J. L. Koenig, J. Polym. Sci., Polym. Phys. Ed., 20, 2135 (1982).

12. C. H. Chiang, H. Ishida, and J. L. Koenig, J. Colloid Interface Sci., 74, 396 (1980).

13. G. G. Cameron and M. S. Chipsholm, Polymer, 27, 1420 (1986).

14. K. Pathmanathan and G. P. Johari, J. Polym. Sci., Polym. Phys. Ed., 28, 675 (1990).

15. Hayakawa, "Busshitsu To Hikari," Asakura Shoten, Tokyo, 1980, p 44.

16. Masaki, "Kougakugijutsu Handbook," Asakura Shoten, Tokyo, 1975, p 1113. 